\title{
FOOD MOTOR CONDITIONED REFLEX AN,J ELECTRICAL STIMULATION OF THE BRAIN STEM RETICULAR FORMATIONS
}

\author{
Hideomi Tuge, Yukitaka Kanayama, \\ and Chang Hui Yueh* \\ Biological and Physiological Laboratory, \\ Hosei University, Tokyo
}

A number of results have been published on the subject of whether the electrical stimulation of the brain is able to serve as a kind of conditioned stimulus. As early as in the 1930s, LoucKs ${ }^{18,19)}$ demonstrated by means of coupling shock to the limb with visual cortex stimulation, that the latter alone evoked limb movement. Although his result raised the question of the method of electrical stimulation employed, recently GIURGEA ${ }^{11)}$ and his collaborators ${ }^{12,13)}$ have made a series of experiments along similar lines to Loucks on brain stimulation and have succeeded in producing a leg flexion conditioned reflex when coupling the electrical stimulation of the occipital cortex with shocks to the motor cortex in the dog. Such cortical-cortical type of conditioned reflex has been called 'shortened conditioned reflex' by Kupalov.

Works of GIURGEA et al. have been extended by DoTY ${ }^{3,4,5)}$ and his collaborators ${ }^{6,7,8)}$ in cooperation with GIURGEA. Their careful studies have clearly confirmed the results made by both Loucks and GIURGeA in dogs and cats. DeLGADO, ROBERTS and MilleR ${ }^{2)}$ observed the formation of avoidance conditioned reflex by coupling the cortical stimulation with subcortical shocks which served as unconditioned stimulus in cats. So far as we know very few studies have been published on the elaboration of the conditioned reflex utilizing electrical stimulation of reticular formation as a conditioned stimulus. LAGUTINA and ROZHANSKI ${ }^{15)}$ found in cats that the food motor conditioned reflex is elaborated by coupling food with electrical stimulation of a certain area in the thalamus (medial n., ventral n., and postero-ventral n.) or in the globus pallidus.

The results above mentioned reveal that electrical stimulation of the brain is possible in assuming the property of conditioned stimulus when coupled with unconditioned stimuli, i.e., either food, pain, or electrical shock applied directly on the motor cortex or subcortical area. An important question, as to whether

Received for publication April 22, 1962.

* 㮌植秀臣, 金山行孝, 張輝岳

Read before the 32nd Japanese Zoological Meeting, Sendai, October 1961. 
such electric stimulation on those structures of the brain can in reality receive a signal meaning, however, yet remains unsolved.

Parallel with these lines of studies, another problem relating to the effect of the brain stimulation during conditioning or on the elaborated conditioned reflex, is of great importance. LISSAK ${ }^{17)}$ and his associates ${ }^{97}$ found that weak electric current on the reticular formations facilitates alimentary conditioned reflex without the introduction of conditioned stimulus. However, this phenomenon does not seem to be clearly elucidated.

Reflecting upon these findings so far, if central stimulation of the nonspecific nervous elements of the brain, i.e., the reticular formations, assumes the character of conditioned stimulus similar to the peripheral receptors, possibility of a change in the signal denotations in the Pavlovian concept must be considered.

The present authors thus undertook the following experiments to discover the characteristics of the reticular formations during the course of studies on the food motor conditioned reflex and the central stimulation.

\section{METHOD}

37 adult rats were used. To elaborate the food motor conditioned reflex, the Skinner box, $15 \mathrm{~cm}$ wide, $28 \mathrm{~cm}$ long and $28 \mathrm{~cm}$ high was employed. A lever was fixed $9 \mathrm{~cm}$ high from the floor, under which a food-tray was equipped to receive a small pellet dropped onto it. The rats used were fed under strict feeding regulations, care being taken not to have them either hungry or in a satiated condition before and during the experimental periods.

After the majority of rats were trained to press the lever for food, they were implanted by stereotactic apparatus with bipolar electrodes in the mesencephalic reticular formations, a few being in the thalamic reticular formations, under nembutal anesthesia. Each of the electrodes implanted for stimulation, insulated with enamel, was $0.1 \mathrm{~mm}$ in diameter at the cut ends, and were fastened together with enamel. A socket in which the electrodes were led was mounted on the cranium with dental cement.

For stimulation of the reticular formations, $2.5 \mathrm{msec}$. square-wave current pulses were delivered from the electronic stimulator, variable 0 to 30 volts. Stimulus frequency was $50 \mathrm{cps}$. Stimuli were monitored on cathode-ray oscilloscopes. Care was taken to isolate all stimulating and monitoring circuits from the ground. Stimulation was administered by the experimenter. Prior to the experiment, all the rats which were to receive the electrical stimulation were tested in order to choose the intensity of stimulation that did not elicit somatic motor movements. Although there were some differences among the experimental animals in their reactivity, the intensity of stimulation found to be adequate for rats was 0.5 volts, which was used throughout the present experiment.

Usually the electric current was charged for $30 \mathrm{sec}$. for coupling in the conditioning experiment, prior to food reinforcement. In order to learn the effect on the cortex by administration of the stimulation with the intensity and duration mentioned above, electroencephalographic records were taken where a slight depression was observed, somewhat more marked than when flickering or sound was introduced. 
White light of $20 \mathrm{~W}$. was also used as a conditioned stimulus. Due to the necessity of differentiation experiment, light of lower intensity was used.

Coupling for conditioning was begun on the 7 th to the 10 th postoperative days. Usually, coupling was less than 8 daily representations of electric stimulation. Cases in which the conditioned lever-pressing was not produced within 30 sec. after introduction of conditioned stimulus were regarded as failure.

At the end of the experiments, the animals were sacrificed and their brains sectioned 10 or $20 \mu$ and stained with thionine or Delafield's hematoxylin to determine the point of electric stimulation. According to histological examination, all the points stimulated distributed within an area of the reticular formations which is situated on the lateral aspect of the central gray, and dorsal of the nucleus ruber and medio-dorsal of the medial lemniscus on the level of emergence of the oculomotor nerves in the mesencephalon. Therefore, points stimulated in the present experiment do not appear to coincide with any points that produce so-called self-stimulation found by Olds and his collaborators ${ }^{23)}$. In the diencephalon, the points stimulated was situated in nucleus centralis medialis and nucleus paracentralis.

\section{RESULTS OBTAINED}

Food Motor Conditioned Reflex formed by Stimulation of the Reticular Formations. Prior to the experiment, a test was made on the rat not pretrained for leverpressing to see whether it pressed the lever by chance when the reticular formation was stimulated. No lever-pressing was observed even 100 presentations of central stimulation during the course of 10 days.

TABLE 1.

Rate of formation of conditioned reflexes.

I

II

\begin{tabular}{|c|c|c|c|}
\hline rat & $\begin{array}{c}\text { Number of reinforce- } \\
\text { ments for stabiliza- } \\
\text { tion of C. R. } \\
\text { (in case of light) }\end{array}$ & rat & $\begin{array}{l}\text { Number of reinforce- } \\
\text { ments for stabilization } \\
\text { of C. R. (in case of } \\
\text { electric stimulation) }\end{array}$ \\
\hline No. 310 & $104(22)$ & No. 310 & 71 (11) \\
\hline , 311 & 94 (11) & , 327 & $46(9)$ \\
\hline „, 312 & 105 (11) & „ 330 & 90 (15) \\
\hline , 313 & $58(7)$ & „ 332 & $56(9)$ \\
\hline , 314 & 121 (17) & " 342 & $142(15) *$ \\
\hline \# 323 & $40(4)$ & , 343 & 66 (11) \\
\hline ” 324 & $50(3)$ & & \\
\hline „ 328 & 56 (11) & & \\
\hline " 331 & $101(9)$ & & \\
\hline " 333 & $35(5)$ & & \\
\hline , 335 & 85 (13) & & \\
\hline \# 336 & 118 & & \\
\hline „ 344 & 39 (12) & & \\
\hline , 345 & $66(5)$ & & \\
\hline
\end{tabular}

Numerals in brackets indicate days for trials. * not stabilized. 


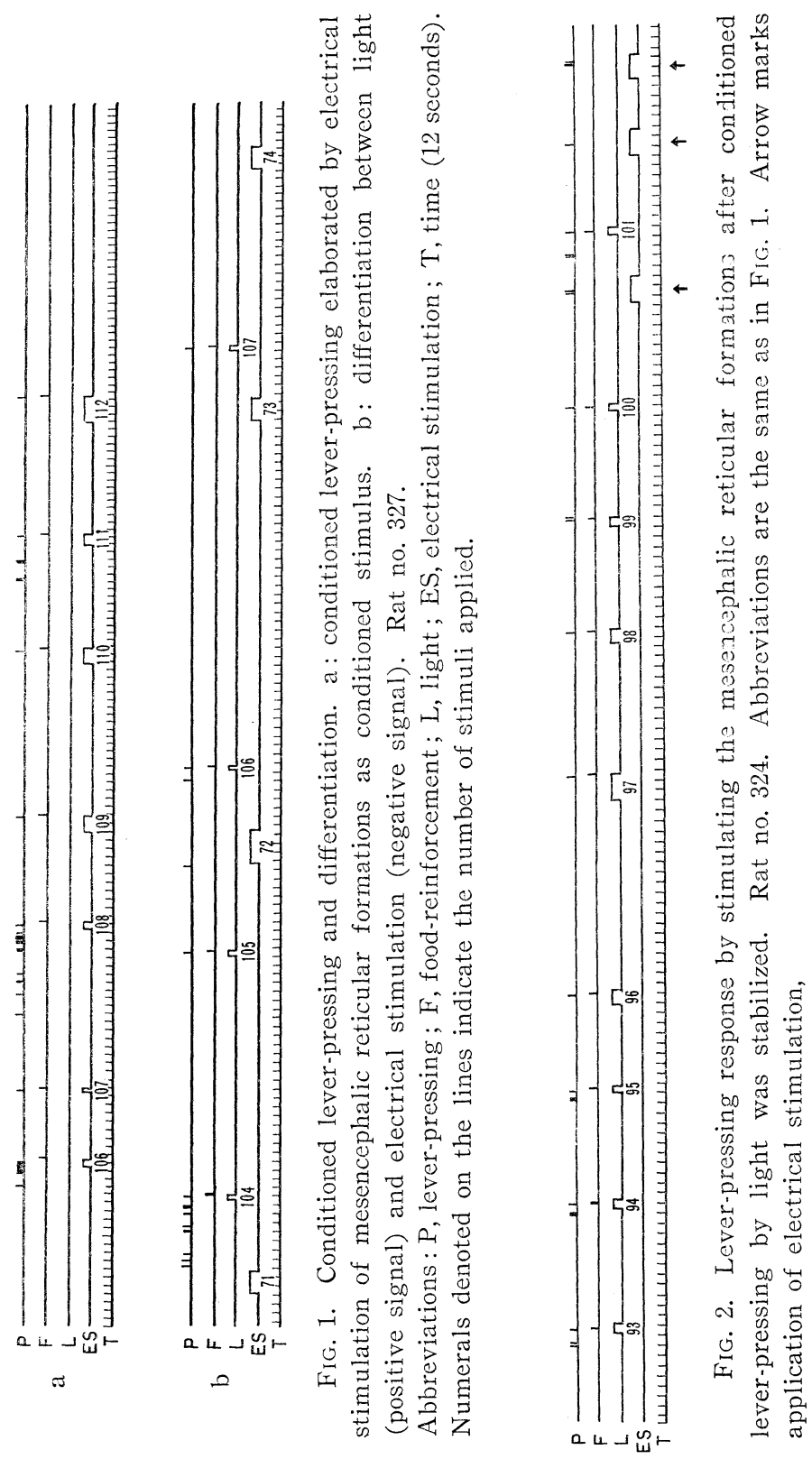

After having been trained to obtain food by pressing the lever in a Skinner box, the rats operated on for electrodes implantation in the mesencephalic reticular formations were coupled for food with an electrical stimulation on the implanted point. After more than 30 couplings, the rats began to press the lever in response to electric stimulation, during which intersignal reactions 
occurred so frequently that there was diffizulty in detecting which was the true conditioned lever-pressing, as is seen in other kinds of animals ${ }^{27}$. According to the reinforcement of food, the intersignal reactions were reduced, the latency of reaction from stimulation to the lever-pressing was shortened, and finally the conditioned lever-pressing was stabilized (FIG. 1a). An example of the reduction in latency will be shown in FIG. 6. A comparison of the rate of formation of conditioned connection at which the conditioned reflex was stabilized in the cases of both reticular formation stimulation and light as the conditioned stimulus, is indicated in TABLE 1 . As is seen from the TABLE, it can hardly be said there is a difference in the rate between them, but rather an indication of the individual variation.

Furthermore in our experiment in which a simultaneous complex of electric and light stimuli was applied as conditioned stimulus, there was no indication that the rate of formation of the conditioned reflex by the complex of stimuli is faster than that of electrical stimulation or light alone. Thus, we were able to prove that central stimulation of the mesencephalic reticular formations as well as the thalamic one possibly plays a role in the elaboration of the food motor conditioned reflex as any peripheral receptor does (FIG. 3).

Effect of Brain Stimulation on Food Motor Conditioned Reflex. Electrical stimulation on the mesencephalic reticular formation was introduced on rats in which the food motor conditioned reflex with light had been established. The observations were very interesting as shown in FIG. 2. Such brain stimulation caused the response of pressing the lever without being exposed to a conditioned stimulus, i. e. light. It may be said that only when the food motor conditioned reflex has been stabilized the administration of the electric current evoked response. The latency counted mostly from 2 to $20 \mathrm{sec}$.

In another experiment, the rats in which the food conditioned reflex was established by means of electrical stimulation of the mesencephalic reticular formations, were stimulated by certain indifferent stimuli, i.e., sound (buzzer, bell or metronome) or light (electric light). In a few cases, such indifferent stimulus alone, particularly light, evoked the response of lever-pressing. However, we could not ascertain it as distinct from the intersignal reaction.

It is not without interest that we note the test on how central stimulation will give effect to the behavior of the rats which have a positive signal for stimulation, in relation to their environmental situation. For example, by administration of electrical stimulation, rat no. 343 behaved as usual in the Skinner box in response to stimulation, pressing the lever for food, whereas when the same electric stimulation was introduced to the same animal in the feeding cage where it was living, it exhibited a very striking behavior. For some ten seconds after administration of the electric stimulation it remained motionless in a squatting position and then ran about wildly in the cage until 
the current was shut off. On the other hand, in another rat (no. 345), the introduction of electric stimulation which was a negative signal in the experimental box did not produce any noticeable response in the feeding cage. It was ascertained after several repetitions of the same procedure. This seems to prove that stimulation of the mesencephalic reticular formations acted as a conditioned stimulus bearing a signal meaning upon these animals.

According to a few examples taken to examine the effect of electrical stimulation on the differentiation which was elaborated between light intensities, it was noted for instance, that when electrical stimulation was administered for $20 \mathrm{sec}$. prior to the introduction of the negative light, no effect was observed (no. 331). The same is true for the positive light, that is to say, despite the introduction of electrical stimulation it caused conditioned lever-pressing (no. 333). Although we did not undertake extinction experiment, we observed in one case (no. 332) after stabilization of conditioned lever-pressing by the conditioned stimulus of electrical stimulation that when it was administrated for 4 minutes, the conditioned reflex was destroyed so completely that it did not recover at all the next day.

Differentiation and Changing of Signal Denotations between Light and Central Stimulation. In order to obtain conclusive evidence of the fact that electrical stimulation of the mesencephalic reticular formations would be able to play the role of conditioned stimulus as does the specific sensory system, it is highly desirable to see how such central stimulation could possibly be transferred from a positive signal to a negative one, and vice versa. To answer this question, we carried out a series of experiments concerning the changing of signal

TABLE 2

Rate of differentiation between electrical stimulation and light.

I II

\begin{tabular}{|c|c|c|c|c|c|}
\hline rat & $\begin{array}{c}\text { weak } \\
\text { differentia- } \\
\text { tion }\end{array}$ & $\begin{array}{c}\text { stable } \\
\text { differentia- } \\
\text { tion }\end{array}$ & rat & $\begin{array}{c}\text { weak } \\
\text { differentia- } \\
\text { tion }\end{array}$ & $\begin{array}{c}\text { stable } \\
\text { differentia- } \\
\text { tion }\end{array}$ \\
\hline No. 318 & $\begin{array}{l}+24 \\
-26\end{array}$ & $\begin{array}{l}+161 \\
-90\end{array}$ & No. 327 & $\begin{array}{l}+44 \\
-30\end{array}$ & $\begin{array}{l}+70 \\
-50\end{array}$ \\
\hline No. 323 & $\begin{array}{l}+67 \\
-47\end{array}$ & $\begin{array}{l}+172 \\
-148\end{array}$ & No. 332 & $\begin{array}{l}+53 \\
-35\end{array}$ & $\begin{array}{l}+75 \\
-50\end{array}$ \\
\hline No. 324 & $\begin{array}{l}+47 \\
-33\end{array}$ & $\begin{array}{c}\text { not } \\
\text { complete }\end{array}$ & No. 343 & $\begin{array}{l}+43 \\
-43\end{array}$ & $\begin{array}{l}+43 \\
-43\end{array}$ \\
\hline No. 344 & $\begin{array}{l}+84 \\
-48\end{array}$ & discont. & & & \\
\hline No. 345 & $\begin{array}{l}+106 \\
-54\end{array}$ & $\begin{array}{l}+207 \\
-106\end{array}$ & & & \\
\hline
\end{tabular}

Numerals denote number of stimuli applied.

$I=$ positive signal-light; negative signal-electric stimulation :

II =negative signal-light ; positive signal-electric stimulation. 


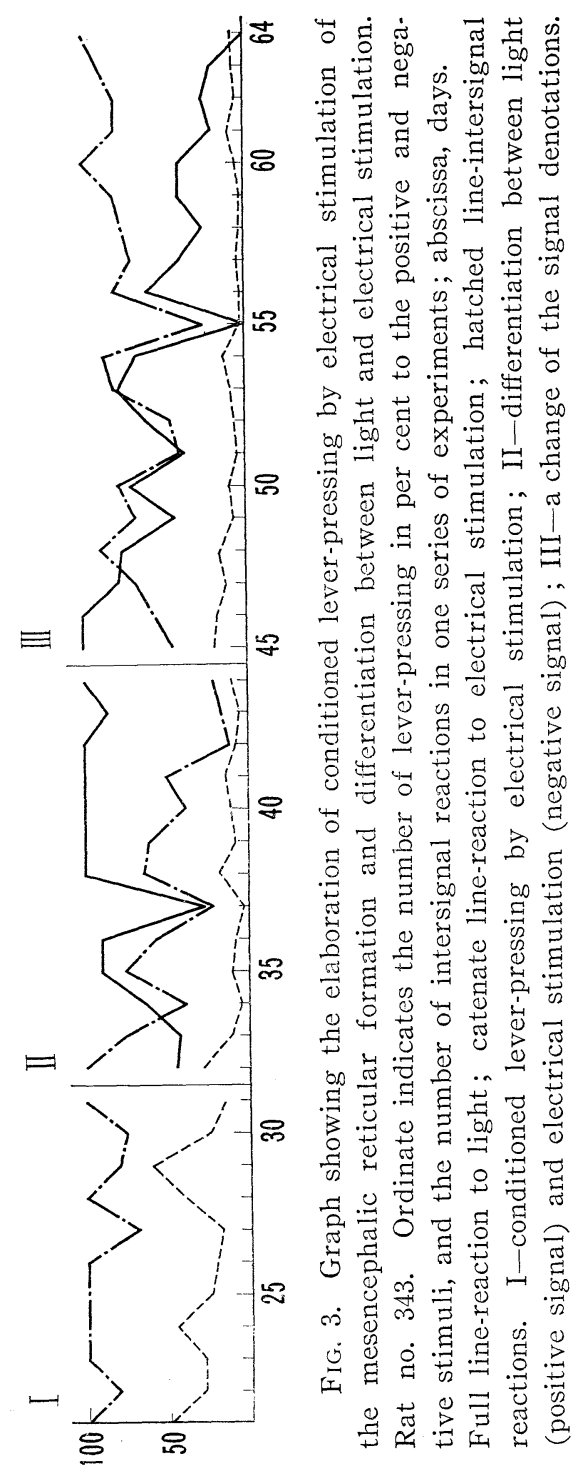

denotations in the Pavlovian concept.

The rats with food motor conditioned reflex by light were stimulated by electrical current in the mesencephalic reticular formations and reinforced with food when the animals pressed the lever, while light that was previously conditioned stimulus, was not reinforced. In most cases at the beginning of this procedure, the intersignal reactions increased. After 67 presentations of electrical stimulation as positive signal and 47 times light as negative, signal there appeared a tendency to transfer the signal meaning, that is to say, the animal 

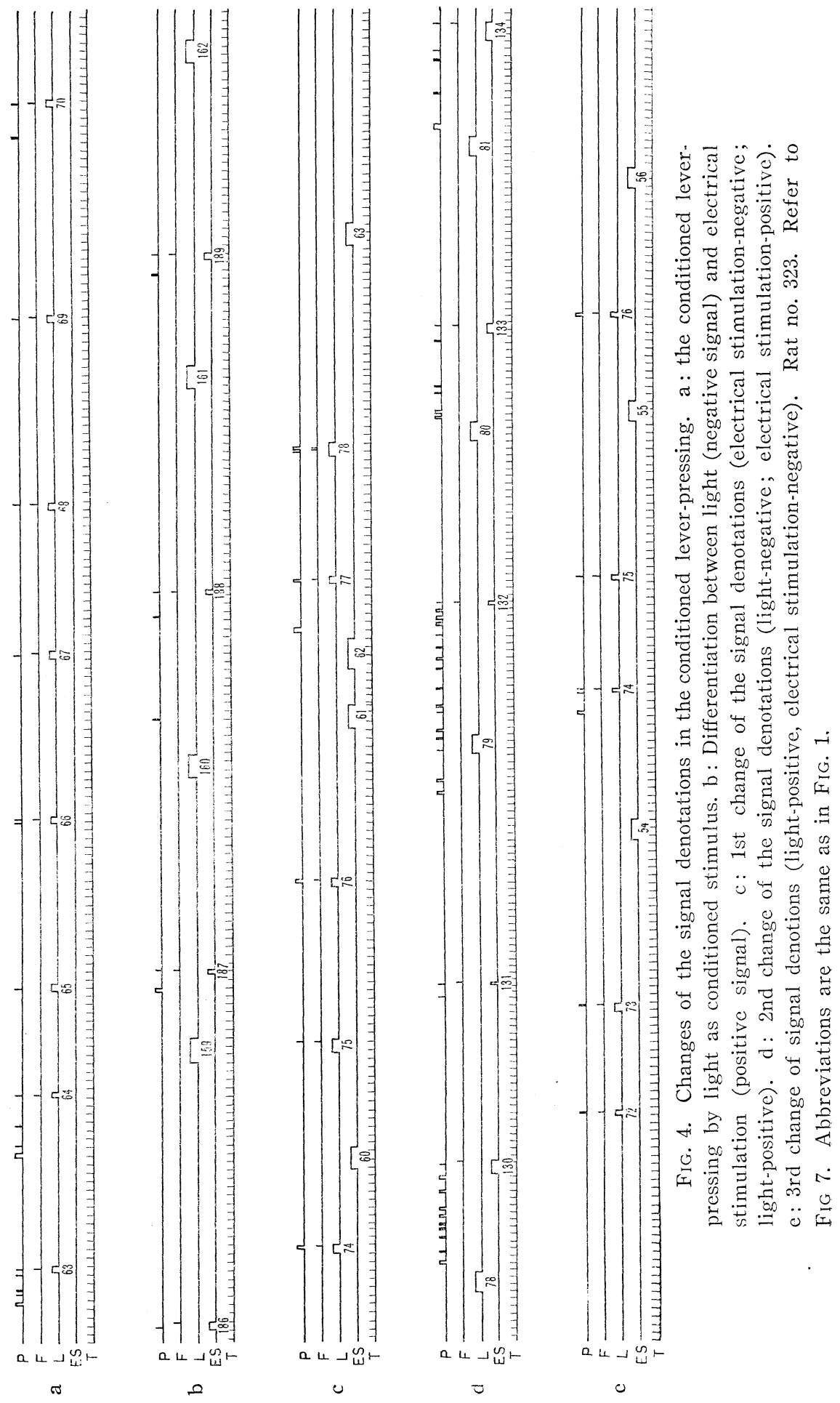

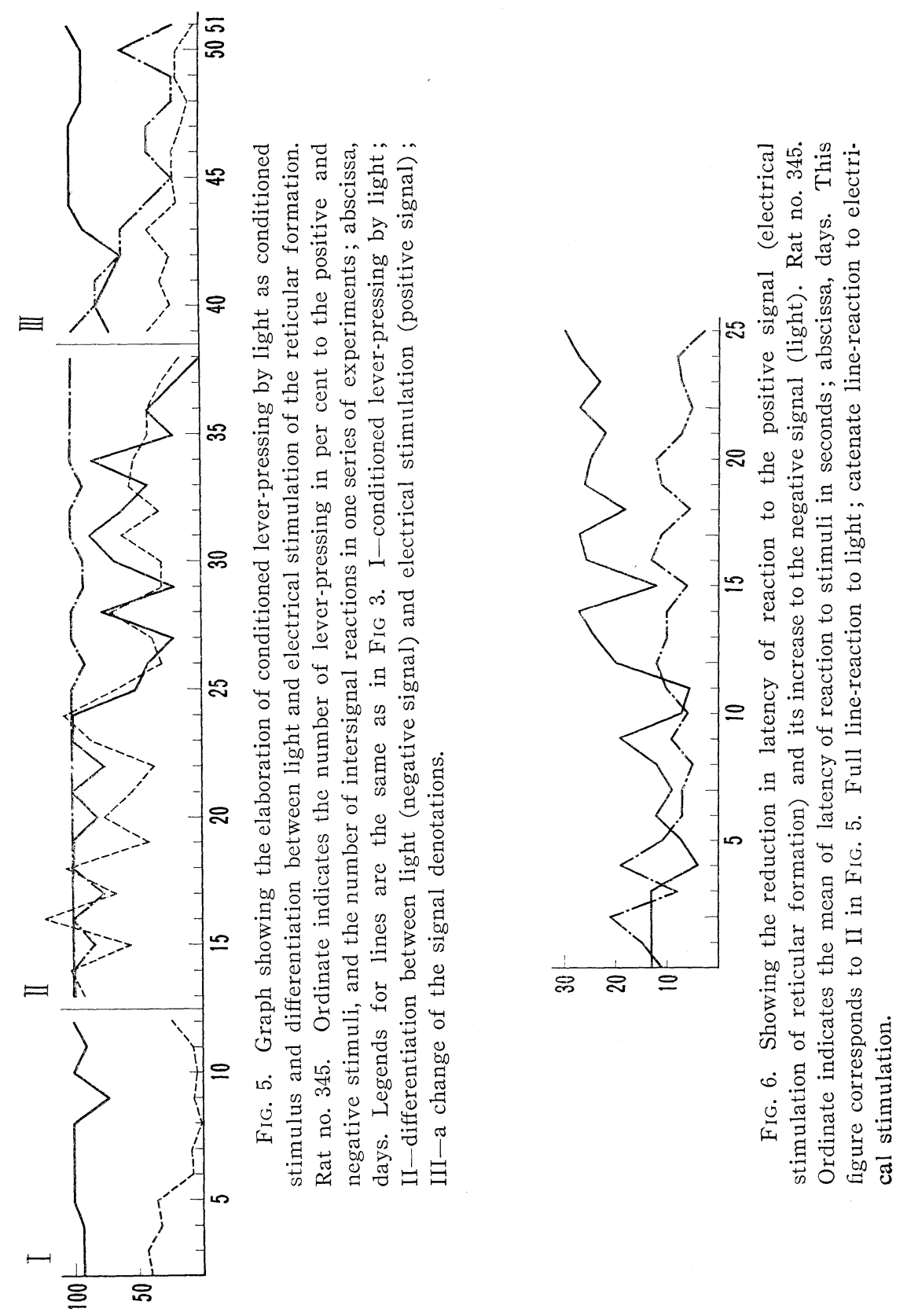


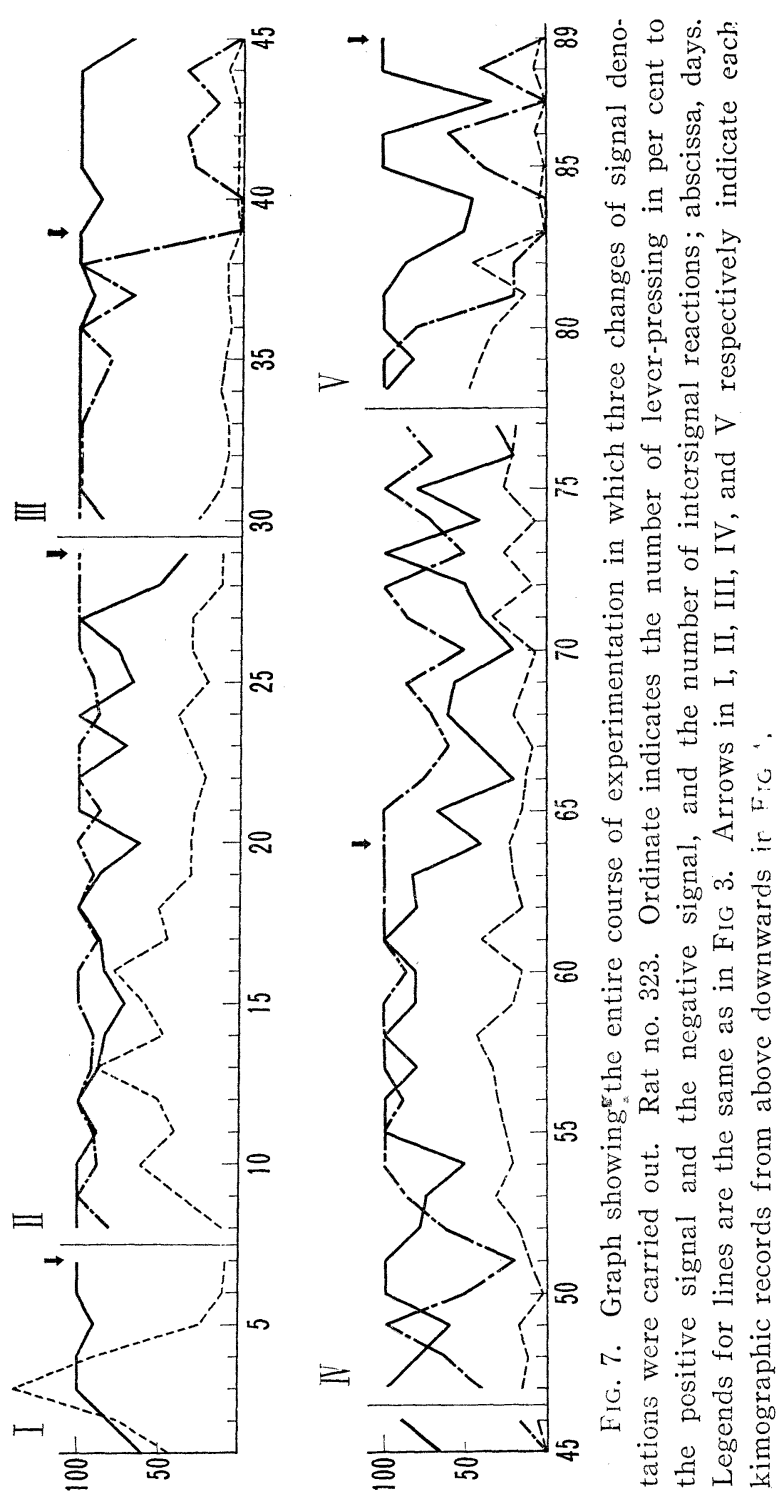

(no. 323) did not press the lever by light, but did by brain stimulation. The process of reduction in latency is shown in Fig. 6. Finally, it was certain that differentiation became complete as shown in FIG. $4 \mathrm{~b}$ and TABLE 2. In some cases where differentiation was accomplished, the signal denotations were changed further again. For instance, the rat (no. 345) that was elaborated with the positive conditioned reflex to light and with the negative conditioned reflex to reticular stimulation was treated with reverse signals respectively. That 
is to say, reticular stimulation was reinforced with food, while light stimulation not reinforced. After 25 presentations of negative signal (electrical stimulation) and 50 times positive signals (light), there appeared a tendency to differentiate between the two signals. Finally, a stable differentiation was successfully obtained. It is clearly proved that electric stimulation of mesencephalic reticular formations is possible of playing the role of conditioned stimulus, whereas stimulation will not work as unconditioned inhibition. In this instance, further changing of signal denotations was not undertaken. However, in another case (no. 323) in which the same procedure was carried out as taken in rat no. 345 , a second changing of signal denotations was made; i.e., positive to electric stimulation and negative to light. This was also solved by the animal, though it exhibited a somewhat neurotic state during this experiment. That is to say, it exhibited increased intersignal reactions, or otherwise was irresponsiveness to both stimuli. But even in this animal the third changing of signal denotations was accomplished without much difficulty (FIGS. 4e and 7).

We also tried the same experiment on rats in which the food motor conditioned reflex had been established by stimulation of mesencephalic reticular formations as a positive conditioned stimulus. In those rats (no. 327, no. 332, no. 343), the reticular stimulation was transferred to the negative signal, and light to the positive signal (TABLE 2). For this training, it required 44 presentations of light and 30 presentations of electrical stimulation in 5 days for a sign of differentiation and 70 presentations of light and 50 times electrical stimulation in 8 days for the stable differentiation (no. 327).

Furthermore, in the one (no. 343) that was successful in transfer of the signal of electric stimulation to the negative signal, again, electric stimulation was reinforced with food and light was not reinforced. In order to accomplish the change of signal meanings as above, it required 147 presentations of electrical stimulation and 117 times light in 20 days. The process of such alterations is indicated in FIG 3.

Together with the results mentioned above, it is clearly indicated it is possible to acquire the meaning of a signal as conditioned stimulus from electric stimulation of the mesencephalic reticular formations, the intracerebral mechanism of which is discussed in a later section.

\section{DISCUSSION}

In the present experiment, in so far as the effect of electric stimulation of the mesencephalic reticular formations facilitating the food motor conditioned reflex is concerned, the following two facts were clarified. 1) the food motor conditioned reflex is elicited without presentation of the conditioned stimulus by administration of electrical stimulation, if its strength is so low that the 
animal does not evoke overt somatic movements. 2) when such electric stimulation is reinforced with food, it plays the role of conditioned stimulus. The same electric stimulation which obtains a positive signal can be transferred to a negative signal and back again to a positive signal, manifesting the possibility of changing the signal denotations in the Pavlovian concept. However, the two facts found in relation to stimulation of the reticular formations must be of a different nature in the neural mechanism involved.

LISSAK $^{17)}$ and his collaborators ${ }^{9)}$ found in dogs that stimulation of the centromedian area of the thalamus and of the reticular formation of the mesencephalon at low voltage facilitated conditioned reflex behavior without having been exposed to the positive conditioned stimulus in the conditioned reflex cage, whereas in the open the same stimulus evoked some previously developed appropriate reactions in the animal. On the basis of their observation, they suggested that this phenomenon may be explained by the interaction between the non-specific diffuse activating system and the specific projection system.

In our experiment, too, the phenomenon discovered by LISSAK and his collaborators was witnessed in the rats. Electric stimulation of the mesencephalic reticular formations caused conditioned lever-pressing previously elaborated with light, but when the electric stimulation acquired a positive signal meaning, in the feeding cage it gave rise to a violent movement some 10 sec. after its administration. Though a satisfactory explanation for the mechanism of this phenomenon in the rat is not as yet complete, we would like to suggest the following: In general, the intersignal reactions are greatly reduced after stabilization of the alimentary conditioned reflex, due to the fact that the experimental situation as a whole will act as a compound inhibitor to inhibit lever-pressing occurring intersignally, whereas stimulation of the reticular formation will give rise to disinhibition so that the lever-pressing will ensue without introduction of the conditioned stimulus. In this connection, mention should be made of MILLER's observation ${ }^{21)}$ that satiated rats trained to press a bar in a hungry state pressed it by electrical stimulation of hypothalamus. Although this phenomenon seems to be similar to those observed by Hungarian school and by ourselves the neural mechanism concerned so far must be quite different because the former case would be due to excitation of the areas related directly or closely to the hypothalamic feeding centers.

Far more interesting than the above finding is that electrical stimulation of the reticular formation enables the animal to assume a signal meaning. According to the current view of neurophysiology, the mesencephalic reticular formation acts in particular as a non-specific diffuse activating system. In the present experiment, we used stimulation of a very weak electric current on the mesencephalic reticular formation almost exclusively, except in a few cases on the thalamic reticular formation. However, our thoughts on this problem are that electrical stimulation whose intensity is so low that no inhibition on 
the reticular-like nervous elements throughout the brain is produced can be a conditioned stimulus when coupled with unconditioned stimulus.

Similar studies on this line were those of GruRgeA, Doty and others, on so-called cortical-cortical or cortical-subcortical conditioned reflex ${ }^{5}$. According to their results, cortical stimulation as conditioned stimulus could be coupled with either direct stimulation of the motor cortex or electrical shock to the limb as unconditioned stimulus in order that the former might evoke defensive conditioned reflex. Another experiment to be mentioned here is the result of LAGUTINA and ROZHANSKI ${ }^{15}$ ) who succeeded in coupling food with electric stimulation of the reticular formations of the thalamus. Thus, the fact that intracerebral stimulation of nervous elements not relating directly to the sensory side can be utilized as a conditioned stimulus must be established. Furthermore, in the present experiment, it was found that stimulation of the reticular formations is transferred into either a positive conditioned signal or a negative one depending upon reinforcement or non-reinforcement.

From the generally accepted view of physiology of the reticular formations, it is hard to understand why electrical stimulation of the reticular formations produces a character of conditioned signal. Some authors report that electrical stimulation of activating reticular system interferes with learned behavior (MILNER $^{22)}$, GLICKMAN ${ }^{14)}$, MAHUT ${ }^{20)}$, but, on the contrary, FuSTER ${ }^{10)}$ finds an improvement in tachistoscopic perception in monkeys. Although there is diversity of results as to the effect of reticular stimulation it may be necessary to take into consideration the following assumptions for elucidation of the facts we detected. First, there is a differential or specific arousal mechanism in the mesencephalic reticular formations revealing possibilities of differential excitation as is supposed by LINDSLEY ${ }^{16}$. Second, it may be due to an irradiation towards the accessory pain-conducting pathways found within the reticular formations by the latter stimulation ${ }^{25)}$. The third possibility is that impulses fired in the reticular formations by electrical stimulation propagate antidromically via collaterals of the medial lemniscus or of the pyramidal tract ${ }^{24}$ and in turn are conveyed as sensory excitation through these tracts up to the higher levels. On the basis of a series of studies on the electroencephalographic analysis of the conditioned reflex activity, ANOKHIN ${ }^{1)}$ arrives at a conclusion that there is some indication of 'the specific biological selectivity of the ascending activating effect of the reticular formations on the cerebral cortex'. The present authors admit, however, that there may be mechanisms other than the mentioned above to explain the phenomenon that electrical stimulation of the reticular formations will serve as a conditioned signal.

Noting particularly that electrical stimulation of the brain must be an artificial stimulus, not occurring under normal conditions in the animal except in some pathological cases, current view of physiology that the brain stem reticular formation will function as a non-specific activating system may have 
to be revised to certain extent in our present study. One of the authors ${ }^{26)}$ in his phylogenetic study of the reticular formations in the bulb came to the conclusion that one of the most important functions of this structure is correlation between the somatic and visceral functions in either the sensory or the motor side. The higher the animal scale in evolution, the more important becomes the cortico-reticular or reticulo-cortical activating system. Nonetheless, the role of correlation in this huge center within the central nervous system should not be excluded in discussing the function of the reticular formations even in higher animals. If be permissible to deduce such a conclusion on the function of the mesencephalic reticular formations, it is not adequate that the reticular formations be a diffusing activating system exclusively to the higher centers. On the contrary, the view tends to favor the idea that the neural mechanism of the reticular formations is somewhat specific as well as nonspecific in function. Final decision must await the results of further investigations dealing with different points of the reticular formations which are being carried out in our laboratory.

\section{SUMMARY}

The effect of central stimulation of the reticular formations at low intensity which does not induce overt somatic movement has been studied in relation to the food motor conditioned reflex, using the Skinner box for rats. Stimulation of the mesencephalic reticular formation induced the previously elaborated conditioned reflex without introduction of the conditioned stimulus. The neural mechanism of this phenomenon has not been explained satisfactorily as yet, but it is suggested that it may be due to disinhibition.

In the present experiment, furthermore, it was ascertained that stimulation of the reticular formations at low intensity possesses the character of conditioned stimulus by coupling with food, in either a positive or negative signal for focd conditioned reflex, i. e., possibility of changing the signal meaning in the Pavlovian concept. Electrical stimulation which indicated a positive signal in the experimental box resulted in giving rise to a striking movement in the feeding cage, notwithstanding the fact that before coupling no change of behavior had been observed with the same intensity of stimulation. Therefore, it is suggested that the current view of neurophysiology of brain stem reticular formations which is regarded exclusively as the functioning of a diffuse non-specific activating system may be revised to certain extent.

\section{REFERENCES}

1) Anokhin, P.K. Electroencephalographic analysis of corticosubcortical relations in positive and negative conditioned reactions. Ann. N. Y. Acad. Sci. 92: 899-938, 1961.

2) Delgado, J.M. R., Roberts, W. W. and Miller, N. E. Learning motivated by 
electrical stimulation of the brain. Am. J. Physiol. 179: 587-593, 1954.

3) Doty, R.W. Brain stimulation and conditioned reflexes. "The central nervous system and behavior (Ed. by A. B. BRAZIER)”. 241-306, 1959.

4) Doty, R. W. The role of subcortical structures in conditioned reflexes. Ann. N. Y. Acad. Sci. 92 : 939-945, 1961.

5) Doty, R. W. Conditioned reflexes formed and evoked by brain stimulation. "Electrical stimulation of the brain (Ed. by D. E. SHEER)". 397-412, 1961.

6) Doty, R. W. and Giurgea, C. Conditioned reflexes established by coupling visual and motor cortex stimulation. Physiologist, 1: 17, 1961.

7) Doty, R. W. and Giurgea, C. Conditioned reflexes established by coupling electrical excitation of two cortical areas. "Brain mechanisms and learning (Ed. by J. DELAFRESNAYA)". 133-151, 1961.

8) Doty, R. W., Rutledge, L.T.JR. and LARSen, R. M. Conditioned reflexes established to electrical stimulation of cat cerebral cortex. J. Neurophysiol. 19: 401-415, 1956.

9) Endröczi, E., Yang, T. L., Lissak, K. and Medgyesi, P. The effect of stimulation of the brain stem on conditioned reflex activity and on behaviour. Acta Physiol. Acad. Sci. Hungaricae, 16: 291-297, 1959.

10) Fuster, J. M. Effects of stimulation of brain stem on tachistoscopic perception. Science 127: 150, 1958.

11) Giurgea, C. Elaborarea reflexului conditionat prin excitarea directa a scoartei cerebrale. Bucharest: Editura Academiei Rep. Pop. Romanc, 1953.

12) Giurgea, C. and Raiciulescu, N. Noi date asupra reflexului conditionat prin directa a cortexului cerebral. Rev. Fiziol. norm. pat. 4: 218-225, 1957.

13) Giurgea, C., Raiciulescu, N. and Marcovici, G. Reflex conditionat interemisferic prin excitarea directa corticala dupa sectionarea corpului calos. Studiu anatomohistologic. Rev. Fiziol. norm. pat. 4 : 408-414, 1957.

14) Glickman, S. E. Retention deficits produced in the rat by stimulation of the ascending reticular formation. Paper read at East. Psychol. Ass., New York, April, 1957.

15) Lagutina, N.I. and Rozhanski, N.A. On the location of subcortical feeding centers. J. Physiol. U.S.S. R. 35: 587-593. 1949.

16) Lindsley, D. B. The reticular activating system and perceptual integration. "Electrical stimulation of the brain (Ed. by D. E. SHEER)". 331-349, 1961.

17) LissaK, K. New experimental aspects in investigating diencephalic mechanism and process of higher nervous activity. J. Higher Nervous Activity, U.S.S. R. 5: 636-643, 1955.

18) Loucks, R. B. Preliminary report of a technique for stimulation of destruction of tissues beneath the integument and the establishing of a conditioned reaction with faradization of the cerebral cortex. J. Comp. Psychol. 16: 439-444, 1933.

19) Loucks, R.B. The experimental delimitation of neural structures essential for learning: the attempt to condition striped muscle responses with faradization of the sigmoid gyri. J. Psychol. 1: 5-44, 1935.

20) Mahut, H. Effects of subcortical electrical stimulation on learning in the rat. Am. Psychologist. 12 : 466, 1957.

21) Miller, N.E. Learning and performance motivated by direct stimulation of the brain. "Electrical stimulation of the brain (Ed. by D. E. SHEER)". 387-396, 1961.

22) Milner, B. Intellectural of the function of the temporal lobes. Psychol. Bull. 51 : 42-62, 1954.

23) Olds, J. Differential effects of drives and drugs on self-stimulation at different brain sites. "Electrical stimulation of the brain (Ed. by D. E. SHEER)". 350-366, 
1961.

24) Scheibel, M. E. and Scheibel, A. B. Structural substrates for integrative patterns in the brain stem reticular core. "Reticular formation of the brain (Ed. by H. H. JASPER et al.)". 37-55, 1958.

25) Spiegel, E. A. and Wycis, H. T. Stimulation of the brain stem and basal ganglia in man. "Electrical stimulation of the brain. (Ed. by D. E. SHEER)" 487-497, 1961.

26) Tuge, H. Somatic motor mechanisms in the midbrain and medulla oblongata of Chrysemys elegans (WIED). I. Comp. Neurol. 55: 185-271. 1932.

27) Tuge, H., Shima, I. and KogA, K. Studies of the conditioned reflex in the lower vertebrates. III. Motor-food conditioned reflex in domestic fowls. Sci. Rep. Tôhoku Univ., Biol. 22 : 115-136, 1956. 